Case Report

\title{
CORONARY ARTERIOVENOUS FISTULA: A CASE REPORT
}

\author{
MZ Chowdhury, MA Bari, AR Khan, AK Miah \\ Department of Cardiology, Bangladesh Institute of Research and Rehabilitation in Diabetes, \\ Endocrine and Metabolic Disorders (BIRDEM) and Ibrahim Medical College, Dhaka
}

\begin{abstract}
The prevalence of congenital abnormalities of coronary artery is about $2 \%$ of general population. Of these abnormalities $5 \%$ were related to coronary artery fistulae (CAF). We report a case of 66 year old diabetic woman who presented with retrosternal chest pain. Her chest pain was associated with exercise and progressively deteriorated over the last 6 months. Electrocardiography showed right bundle branch block and Echo Color Doppler revealed hypo kinetic lateral wall. Coronary angiogram detected nothing abnormal except an aberrant tortuous branch of left circumflex. CT scan revealed a calcified sac medial to the descended thoracic aorta. A contrast enhancement was also done. All these imaging impressions were suggestive of coronary-to-pulmonary fistula.
\end{abstract}

Ibrahim Med. Coll. J. 2007; 1(1): 32-33

\section{Introduction}

A congenital coronary arteriovenous fistula is an anomaly that consists of a communication between a coronary artery and either atrium or ventricle (coronary cameral fistula) or coronary sinus, superior venaecava or pulmonary artery (coronary arteriovenous fistula). Sometimes both of these groups are included under one or the other name ${ }^{1}$. It is observed in $0.1 \%$ to $0.2 \%$ of coronary angiography studies ${ }^{2}$.

\section{Case report}

A 66yr old diabetic, hypertensive lady was admitted into BIRDEM hospital with the complaints of gradually progressive retrosternal chest pain on exertion for six months. On examination pulse rate was $96 / \mathrm{min}$, BP $150 / 90 \mathrm{mmHg}$. There was no oedema or raised jugular venous pressure. Aortic component of the second heart sound was louder. Other system examination revealed no abnormality. On investigation, electrocardiography showed right bundle branch block (RBBB) with anterolateral ischemia while the chest radiography was normal. Echo color Doppler showed hypo kinetic lateral wall with good left ventricular systolic function (ejection fraction 66\%). Relevant haematological and biochemical profiles including cardiac markers were normal. For evaluation of coronary status, angiogram was done which showed no significant lesion in left main, left anterior descending or right coronary artery. In left circumflex (LCx) no significant lesion was seen but an aberrant tortuous branch of LCx was seen, which was suggestive of probable coronary artery fistula. Impression was normal epicardial coronary arteries with probable coronary fistula. A CT scan was done which showed a sac like area $(28 \times 22 \times 18 \mathrm{~mm})$ in the prevertebral region, postero-inferior to the carina and medial to the proximal part of descending thoracic aorta. The walls of sac were calcified and there was contrast enhancement of the area, which communicates with a tortuous vessel. The tortuous vessel ran down the aortic arch and reached the left side adjacent to the left hilum around the pulmonary artery where multiple sarpigeneous vascular channels were evident. Imaging impression suggested coronary-pulmonary artery fistula. So our final diagnosis was ischemic heart disease due to coronary-to-pulmonary fistula with Type 2 Diabetes mellitus and hypertension.

\section{Discussion}

Congenital abnormalities of coronary artery occur in $1-2 \%$ of general population. These abnormalities may be of origin, distribution and termination.

Address for Correspondence:

Dr. MZ Chowdhury, Department of Cardiology, Ibrahim Medical College \& BIRDEM

122 Kazi Nazrul Islam Avenue, Shahbag, Dhaka-1000 


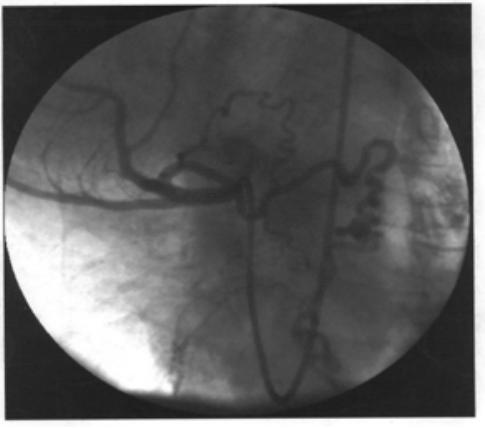

Fig 1 : Coronary Angiography showing coronary artery fistula between the left Circumflex coronary artery and the pulmonary artery, shown in the right oblique view. The angiogram was performed that Ibrahim Cardiac Centre by one of the authors.

Coronary artery fistulae (CAF) are considered to be termination abnormalities ${ }^{3}$. CAF accounts for 0.2$0.4 \%$ of congenital cardiac anomalies. Approximately $5 \%$ of coronary anomalies are $\mathrm{CAF}^{4}$. Common sites of fistulae are right coronary artery or its branches $(55 \%)$, left coronary artery or its branches $(35 \%)$ or both $(5 \%)^{5}$. Embryologicaly, persistence of some of the inter-trabecular spaces in the primitive myocardium lead to coronary cameral fistula. On the other hand communication between the primitive coronary artery and mediastinal plexus of vessels gives rise to fistulae from coronary artery or pulmonary artery or bronchial artery or mediastinal artery. The fistulous coronary artery may be small or large and tortuous, and it enters the effected chamber by one or several openings. Small fistula does not cause any haemodynamic effect but large fistula causes left to right shunt large enough to cause volume overload though significant pulmonary hypertension is rare. Significant run off through the fistula may decrease flow through more distal coronary artery and cause a coronary steal ${ }^{1}$. Male and female is equally effected. Small fistula is asymptomatic. In large fistulae, symptoms are rare before 20 years of age. Symptoms include fatigue, exertional dyspnoea and chest pain. The latter is usually seen in $80 \%$ of the patients over 50 years. On examination there is thrill and continuous murmur on the mid left or right sternal border louder in mid diastole. It may be absent if LCx is involved. There may be features of complications like congestive cardiac failure, pulmonary hypertension, myocardial ischemia, bacterial endocarditis and saccular aneurysmal dilation rarely leading to spontaneous rupture. For diagnosis electrocardiography, chest radiography, transthoracic echocardiography (2-D \& Doppler colour flow), transoesophageal echocardiography, coronary angiogram or laid back aortogram or CT scan can be done ${ }^{5}$. Except for the very small, most coronary arteriovenous fistulae should be closed by ligation, microparticle embolization or wire coils ${ }^{6}$. Prognosis is excellent if closure is done early before development of any complication.

Our patient presented with angina. As she had normal epicardial coronary flow, her angina was probably due to significant run off through the fistula causing a coronary steal. In our case we did not find any thrill or continuous murmur as the LCx was involved. As congenital coronary fistula can be corrected with surgery, the patient was referred to a cardiothoracic surgeon, but the patient refused to go for any surgery.

\section{References}

1. Hoffman JIE. Congenital Anomalies of the Coronary vessels and the aortic root. In: Moss and Adam. Eds. Heart Disease in Infants, Children and Adolescents. $4^{\text {th }}$ edition. Williams and Wilkins, Baltimore, 1989: 769-790.

2. Athanasias DA, Ommen VV, Bar F: Coronary arterypulmonary artery fistula originating from the left anterior descending artery: A case report and literature review. Hellenic J Cardio 2002, 43: 78-81.

3. Darwazah AZ, Hussein IH, Hawari MH. Congenital Circumflex Coronary arteriovenous Fistula. Texas Heart Institute Journal 2005; 32: 56-59.

4. Pelech AN (18 July, 2002). Coronary artery fistula. Available from: eMedicine. com/PED/Topic 2505.htm [Accessed 6 ${ }^{\text {th }}$ Dec. 2005]

5. Friedman WF, Silverman N. Congenital Heart Disease in infancy and childhood. In: Braundwald E, Zipes DP, Libby P. Eds. Heart disease $6^{\text {th }}$ edition WB Saunders, Philadelphia, 2001: 1505-1582.

6. Futon DR and Freed MD. The pathology, pathophysiology, recognition and treatment of congenital heart disease. In: Fuster V, Alexander RW, O'Rourke RA. Eds. Hurst's The Heart. 11 ${ }^{\text {th }}$ edition; McGraw-Hill, New York, 2004: 1785-1844. 